\title{
The history of Community Interpreting studies in Japan
}

\author{
Makiko Mizuno \\ Senri Kinran University, Japan
}

The study of CI in Japan began in the late 1980s, and its first researchers were law professors and attorneys who advocated human rights. They discussed the plight of non-Japanese-speaking defendants in legal settings. Subsequently, interpreters and theorists of interpretation discussed ethics, cultural issues, training and so on. Recently, however, a new wave of studies has emerged, with a greater focus on linguistic approaches such as discourse analysis, corpus studies etc. This paper will first briefly review the earlier CI research in general and then focus on legal interpreting, which is the most advanced and noteworthy area of CI studies in Japan.

\section{Introduction}

In Japan, the concept of community interpreting (CI) was completely unknown until about two decades ago. Japanese society had long been characterized by homogeneity and uniformity until the time of the so-called bubble economy, an economic boom that occurred in the period between the latter half of the 1980s and the early 1990s. This boom attracted a large number of immigrant workers from all over the world, particularly from Asia and South America and as, unfortunately enough, the number of criminal cases involving such foreign workers became significant, the Japanese judiciary began to realize the need for legal interpreting and translating. For the first time, the existence of other areas of interpreting besides conference interpreting was acknowledged, whereas until then, research into interpretation in Japan had been restricted to the area of conference interpreting.

Research into this new interpreting context, that of legal interpreting, can be roughly divided into four different phases, representing the periods between 1990 and 1995, 1995 and 2000, 2000 and 2005 and from 2005 onward. Each of these phases is characterized by a different societal background and a different type of approach to the issue. This paper will describe the background, contents and characteristics, contributions and shortcomings of each research phase. First, however, it will briefly survey other areas of CI focusing on health care interpreting more in particular.

It is hoped that this overview will offer some insight into the typical patterns of CI research and its evolution in a non-immigrant country like Japan. 


\section{CI Studies in general}

Until the 1980s, there were practically no publications at all on interpreting in Japan. The early contributors to this esoteric field of study were conference interpreters, and they mainly focused on issues related to conference interpreting and its historical, societal or cultural background (e.g. Nishiyama 1988; Kondo 1988). Studies on CI began to gain prominence only from around 1990. Until then, most of the research projects related to the nonJapanese speaking people in Japan were focused on the conditions they faced in their new environment. Researchers in this area were mainly economists, sociologists and jurists, and they discussed above all human rights issues related to the immigrant population, such as access to social services, health care, education and so forth. For example, a well-known scholar in this field, Tezuka (1989), focused on this issue from the legal and economic point of view. If these early researchers discussed the issue of communication, they did so only briefly.

From around 1990, several local governments began to conduct surveys in order to identify the linguistic needs of foreigners residing in their jurisdiction. The focus of these surveys was on social service sectors, but no significant research was conducted into the issue of language mediation or interpretation. More recently, because of growing concern about education for children who do not speak Japanese, the issue of the importance of and need for school interpreters has begun to draw attention but, on the whole, since Japan had for so long been a non-immigrant country, the service needs of non-nationals had been regarded as 'exceptional'.

Another interesting observation is that in Japan, sign language interpretation had seldom been discussed in the context of CI until the early nineties. As a matter of fact, spoken language and sign language interpretation had been treated as completely separate areas and there had been no attempt to combine these two types of interpreting. The book Hearing-impaired and Criminal Procedures (Matsumoto et al. 1992) was the first publication that dealt with sign-language interpreting in the framework of CI. It was based on case studies, and it also referred to a couple of cases of miscommunication in medical settings.

Health care interpreting is an emerging area of study too. From around 2000, NPOs, such as MIC Kanagawa ${ }^{1}$, have launched various kinds of projects related to the dispatch and training of health care interpreters. This trend has led to an increased awareness among health care providers about the quality of interpreting in medical settings. In this particular area, there have been three different types of approaches.

First there is the statistical approach. Surveys of communication needs have been conducted by doctors, nurses and social workers at several medical institutions that are visited by a large number of non-Japanesespeaking patients. Although there have been no significant publications to date, on various occasions, such as during conferences and seminars, some data have been presented. These throw some light on the numbers and nationalities of the patients, their ailments at the time of visiting the institu- 
tion, whether or not they had health insurance, the number of times that they experienced communication problems, the manner in which staff in that particular institution handled language-related issues and so forth.

One noteworthy statistical study was undertaken by researchers of KDDI (a telephone company) Research Institute, Inc. This study was fairly unique, because one of the themes it dealt with is a method of utilizing machine translation systems for medical treatment. Their report was submitted to the International Communication Foundation (KDDI Research Institute, Inc. 2005).

The second approach is an educational one. In 2003, MEDINT (Medical Interpreters Association) in the Hyogo Prefecture, for instance, launched programmes to train both interpreters and health care providers. They hold regular study sessions on various themes, such as the symptoms of and medication for various diseases. Some other organizations have initiated similar programmes. The study of ethical issues has been an integral part of such training modules. For example, a symposium on the ethics of health care interpreting was held in Osaka on 6 November 2005, hosted by MITF(Medical Interpreting Task Force), a group comprising the representatives of five organizations related to health care interpreting, such as MEDINT, and the Mainichi Newspaper Company. At this symposium, the Code of Ethics of the US National Council for Health Care Interpreters was introduced; the translated version of the Code has also been published (MITF 2006).

The final research methodology is that of undertaking overseas studies. The primary interest of the researchers active in this field has been to determine how systems of health care interpreting should operate and how interpreters should be trained. Traditional immigrant-recipient countries, such as the US, Australia and Canada have been the main focus of such studies and there have already been some publications by health care providers on these issues, for example, the article by Ishizaki (2004) on the (U.S.) Washington State system.

Training courses, such as Bridging the Gap ${ }^{2}$ offered by the Cross Cultural Health Care Program in the US, have also served as a good resource for studying training methods. Another important event in terms of overseas studies was the national conference on health care interpreting that was held in Yokohama on 28 January 2006. This conference addressed three themes in three sessions. The first session discussed the present status of and challenges to the system of health care interpreting with practising doctors as resource persons. The second discussed desirable training systems for interpreters. The resource persons here were programme organizers and interpreting trainers. In the third session, the representatives of public organizations discussed the institutionalization of health care interpreting. For this conference, the host organization, MIC Kanagawa, carried out extensive research into overseas systems and presented such systems in advanced case-studies (MIC Kanagawa 2006). Perhaps most importantly of all, through this conference a nation-wide network of health care interpreters and their users was established. This event has therefore been of great sig- 
nificance for the field of CI, particularly that of medical interpreting because it has enabled a smoother flow of information. Moreover, such a network of people from various backgrounds will no doubt contribute significantly to the future advancement of research in this area.

\section{Legal Interpreting: the first phase 1990-1995}

\subsection{Background}

It was during the period of Japan's bubble economy that the presence of non-Japanese people suddenly began to become 'conspicuous' to the authorities. It was unusual for the Japanese to encounter non-Japanese-speaking people in various places such as schools, government offices, hospitals and courtrooms.

Among all the settings in which non-Japanese people were involved, it was in the criminal courts that language problems had the most serious implications. In these settings, the language problems would be visibly and directly linked to possible miscarriages of justice. Therefore, the area of court interpreting, or legal interpreting, first and foremost drew the attention of human-rights-oriented scholars.

\subsection{Topics and characteristics of the studies}

Although a number of studies concerning foreigners before 1990 did mention communication issues, there was no mention of interpreting and translation. But from around 1990 on, interpretation and translation came to be discussed as distinct issues in the judiciary. Scholars of law mainly discussed legislation related to the issue of legal interpreting (e.g. Asada 1994); practising lawyers, on the other hand, discussed the issue mainly from the human rights point of view. For example, the Osaka Bar Association published a report (Osaka Bar Association 1991) in which they compared international and domestic laws, and discussed the right to due process and equal protection under the law. Some introduced the situation regarding legal interpreting in other countries to Japan. In 1988, the US Congress passed legislation amending the Court Interpreters $\mathrm{Act}^{3}$, which served as a good source for research in Japan as well. Ebashi (1990), for example, surveyed the precedents in common-law nations in which legal interpreting was an issue and discussed the right to a fair trial in this context. The law enforcement agencies also presented their views on the same issue (e.g. Shimane 1992). 


\subsection{Contributions and shortcomings}

It has been pointed out that studies of legal interpreting began with the initiatives by both practising lawyers and scholars of law. Through their works, the idea that foreigners in Japan were facing problems of non-communication or miscommunication, which implied a violation of their right to a fair trial, became widely recognized.

In this phase, however, there was as yet no substantial contribution from practising interpreters or linguists. The principal researchers were people who did not possess any knowledge of interpreting or translation. For example, Okabe (1991) published a highly informative article about the federal system of court interpreting in the US. However, the contents of his article clearly suggest that he had no insight in how consecutive interpretation works, and misunderstood its meaning. This example typifies this first research phase.

\section{Legal Interpreting: the second phase 1995-2000}

\subsection{Background}

As the number of foreign nationals in Japan continued to increase, also crimes committed by them, particularly felonies, became more widespread and, consequently, legal interpreting became an urgent issue to be tackled. Against this background, collaboration between lawyers and practising interpreters was initiated. One of the typical examples is the collaboration between the lawyers of the Osaka Bar Association and the interpreters working in the courts falling under the jurisdiction of the Osaka High Court. Many of the interpreters who participated in this collaboration were members of the Japan Judicial Interpreters Association (JJIA), which was established in 1992. JJIA is the largest nation-wide group of legal interpreters and aims to both acquire and share information about important issues related to their work. They often conduct mock trials or mock interrogations, using scenarios that have been prepared by lawyers, and they exchange opinions and ideas on certain issues that have surfaced during such mock situations.

Another noteworthy phenomenon is that this period corresponds with the time when the number of universities and colleges where interpretation programmes were introduced, increased dramatically. University training in interpretation and translation had already begun in the 1960s; however, it was limited to a few universities with 'special interests' only. The new developments of the mid-1990s attracted a considerable number of new potential professional interpreters to academia. 


\subsection{Topics and characteristics of the Studies}

Through the collaborative efforts of lawyers and interpreters, studies in legal interpreting took a giant stride during this phase. At the time when most of the research was undertaken by those related to the field or discipline of law, the range of issues covered was fairly limited. In this period, however, many practising interpreters entered the field, and the themes discussed became more diversified.

The members of JJIA were the primary contributors to the field, contributing articles to JJIA's own journal as well as other academic publications. Mizuno (1995) discussed the possibilities of certifying legal interpreters in Japan. Tsuda (1997) illustrated the overall problems faced by foreigners in Japan's criminal justice system. Particular cases involving nonJapanese defendants were discussed, most often cases involving lesser-used languages such as Thai. The so-called Dogo Case $e^{4}$ was one of the most famous of such cases involving the issue of interpreting (Kimura 1998). By using these cases, researchers attempted to show how poor interpreting affected the defendants' rights to a fair trial and to equal protection under the law. Discussions were also held on cross-cultural issues, on ethics and so forth. In 1998, Osamu Watanabe, a leading scholar in criminology, and Hiromi Nagao, a practising legal interpreter and the president of JJIA, compiled a book entitled Foreigners and Criminal Proceedings (Watanabe \& Nagao 1998). This book consists of articles written by both interpreters working in various languages and practising lawyers. They introduced specific problems that they themselves had faced during criminal proceedings.

In the meantime, there had been sporadic publications of articles on CI, particularly legal interpreting, contributed to Japanese journals by overseas researchers. For example, Pinkerton (1996) introduced the Australian system of legal interpreting and compared it with the Japanese system.

\subsection{Contributions and shortcomings}

Collaborative research generated an enhanced mutual understanding between lawyers and interpreters, as it proved to be advantageous to interpreters to understand the legal system and terminology, and to lawyers to recognize the difficulties that interpreters faced.

During this period, there were substantial publications on legal interpreting, including the above mentioned book and journals, and the problems surrounding legal interpreting came to light in a concrete form. Interpreters who had been at a loss in coping with their difficult tasks now had concrete resources; moreover, legal entities, including the Ministry of Justice of Japan, became aware of the problems inherent in the area of legal interpretation.

In this phase, however, there were still no in-depth studies into the mechanism or skills of interpreting. Most of the studies were concentrated 
on case studies that allowed for the collaboration of legal experts and interpreters.

\section{Legal Interpreting: the third phase 2000-2005}

\subsection{Background}

The most important development in this phase was the launch of overseas studies by the Ministry of Justice. Beginning in the year 2000, the Ministry dispatched researchers to the countries in which legal interpreting systems were considered to be well developed. This meant the United States (fiscal year 2000), Germany, France and Sweden (2001), Australia (2002), Britain and Spain (2003) and Taiwan, Singapore and Hong Kong (2004). The researchers, who were mainly from academia, visited key institutions including courthouses in each country and conducted interviews with judges, attorneys, interpreters, researchers and educators in this field. They gathered information about the laws that governed legal interpretation, the manner in which legal interpreters were certified and received their assignments and so on; the data collected was compiled in reports submitted to the Ministry by each research group.

Another incident that turned the Japanese researchers' attention toward overseas cases was the Melbourne Case, in which five Japanese tourists in Australia had been convicted of drug smuggling. Due to poor interpretation during the police interview and court trial, their claim of innocence was not communicated in a sufficiently effective manner to the investigators and the jurors. They then sought remedy by filing an 'Individual Communications' claim with the United Nations Human Rights Commission. A group of Osaka-based attorneys compiled additional legal and factual arguments in support of the Communications (Yamashita 2001). They transcribed the taped police interview and commissioned experts to analyze the quality of the interpretation.

Meanwhile, the International Conference on Interpreting in Legal, Health, and Social Service Settings, commonly referred to as The Critical Link, as well as other international meetings on similar themes became known among Japanese researchers, and the number of Japanese participants in such meetings gradually increased. At The Critical Link 3 Conference, for example, Nagao (2001) surveyed the status of legal interpreting in Japan.

Another noteworthy development was the establishment of advanced interpretation and translation courses for graduate students by some prestigious universities. Among them, the Osaka University of Foreign Studies launched a Master's course in 2004 to train interpreters and translators for the judicial and medical fields as well as for community services. This was the first instance of CI studies being incorporated in the official curriculum of a graduate school. 


\subsection{Topics and Characteristics of the Studies}

The intense collaboration between lawyers and interpreters which had been launched in the previous phase, bore fruit in the form of a book entitled $\mathrm{Le}$ gal Interpreting (Watanabe et al. 2004). This book comprises three chapters, viz. 'Outline of Criminal Procedures', 'Legal and Technical Terminology' and 'Code of Ethics for Judiciary Interpreters'. The contents of these chapters are based on the materials used for the joint workshops and seminars for lawyers and interpreters. This book in a way crystallizes the joint collaborative research undertaken by lawyers and linguists, including interpreters.

As mentioned earlier, researchers who were sent abroad by the Ministry of Justice, including the authors of Legal Interpreting, published papers and articles and made presentations at academic conferences in order to introduce what they had learnt about the systems abroad (e.g. Mizuno 2004). Consequently, studies on overseas systems of legal interpreting made considerable progress. A major part of the research into overseas situations in this phase was now undertaken by interpreters or by theorists of interpretation. As a result, the focus of study shifted from laws and judicial systems to more specific matters directly related to interpreting - for example, how legal interpreters were certified, trained and appointed, what their working conditions were, what constituted ethically important issues and so forth.

\subsection{Contributions and shortcomings}

As pointed out above, one of the most noteworthy contributions to the field in this period was the publication of the book Legal Interpreting by Watanabe et al. (2004). In this book, all the stages of criminal procedures are discussed and various situations in which interpreters might face difficulties are illustrated. The book also discusses linguistic issues, taking examples from legal terminology and focusing on words and phrases that pose particular translation difficulties. In addition, dialogues or exchanges that are difficult for interpreters to translate, such as an incoherent witness testimony or typical, culturally bound Japanese ways of phrasing, are scrutinized, and suggestions for accurate interpretation are made. The authors chose the terms, phrases or expressions that were included on the basis of a survey of the problems practising interpreters had encountered while performing their tasks. The linguistic approach taken in the book has meanwhile provided a basis for further studies in discourse analysis, one of the trends we will see emerging in the next phase.

In contrast to these developments in the study of criminal procedures, however, few or practically no contributions were made to the area of civil proceedings. Japan is not really a litigious society and the number of non-Japanese people who might actually go to the lengths of filing a lawsuit is still small. As a result, interpretation in civil cases has not really become an urgent issue as yet. 
The large number of Japanese researchers participating in conferences or conducting research overseas increased the direct contact with researchers in other countries, and served as one of the stimulants in recognizing the importance of $\mathrm{CI}$ as a distinctive discipline. Collectively these trends contributed to positioning $\mathrm{CI}$ as a new area of academic study. This was reflected in the launch of a CI Special Interest Group (CI SIG) within the Japan Association for Interpretation Studies (JAIS) in 2003, a nationwide academic association whose primary focus until then had been conference interpretation. Against this background, legal interpreting began to be discussed in the context of CI for the first time. Simultaneously, the number of graduate students who chose to study this field increased dramatically, and their articles began to appear in academic journals, one example being Nishimatsu (2003).

Still, even though some linguistic aspects of legal interpreting were addressed during this period, no solid study was conducted as yet from the viewpoint of forensic linguistics.

\section{Legal Interpreting: the fourth phase, from 2005 onward}

\subsection{Background}

By this time, 2005, the field of legal interpreting had matured both in terms of overseas studies and the analysis of how these systems operate. The really new development in terms of CI study was the launch and implementation of an academic association known as the Japan Association for Public Service Interpreting and Translation (JAPSIT) in 2005. JAPSIT specializes in CI, in contrast to JAIS, which has a SIG for CI as one of the study fields under the umbrella of interpretation studies. Legal interpreting is now one of the three pillars of JAPSIT.

In the period from 2005 onward, there has been a kind of shift among researchers in terms of the approach to their field. Particularly in the domain of legal interpreting, researchers' attention has now turned towards more linguistic approaches, such as discourse analysis and corpus studies. This is partly because of the scheduled introduction of the so-called citizen judge system in 2009, which is similar to the jury system. The manner in which speeches in court may influence verdicts by citizen judges has now become an issue of concern among lawyers. It seems obvious, therefore, that the pragmatics of court speeches and their interpretation has come to attract the attention of researchers.

\subsection{Topics and characteristics of the Studies}

Because the quality of scholarship has been improved in the field of interpretation studies on the whole, more scholarly academic approaches are now being attempted. 
Linguistic approaches are the most noteworthy development, with the issue of equivalence as one of the popular themes. Mizuno (2006), for example, analysed the linguistic structures of judges' sentencing decisions and discussed the strategies of producing semantically equivalent translations without undermining legal equivalence.

Another phenomenon is that, as a preparatory step towards the impending introduction of the citizen judge system, corpus studies are drawing the attention of an increasing number of researchers as an efficient method of obtaining statistical data regarding frequently used expressions in trials. The CI SIG of the JAIS has initiated a study project on this theme, and had the first academic meeting on corpus studies in July 2006. There is no doubt such efforts will produce interesting results in the forthcoming years.

\subsection{Contributions and shortcomings}

Since the research has become more linguistic and academic, researchers now have to face the challenge of accessing real spoken data. This may be problematic because, first of all, interrogations by the Japanese police and prosecutors are not audio-taped, nor are trials in Japan televised. Trials are audio-taped, however, when interpreters are used but it is impossible to obtain permission to listen to the tapes, except in special cases where it is absolutely necessary for attorneys to analyze the tapes for legal reasons, and in the process of carrying out their duties. If a researcher wishes to obtain the data of court speeches or interpretations, he or she has to be physically present in the court and try to write everything down in shorthand. But corpus studies, of course, require a large number of data and the main challenge faced by researchers today is to find a way of coping with this difficulty.

\section{Conclusion}

Community Interpreting studies in Japan really took off in the area of legal interpreting first and it was only after a delay of nearly ten years that the area of health care interpreting also began to draw attention. However, progress in the area of health care interpreting appears to be faster than that in the legal area, because researchers have been following the path laid down by their colleagues working in the area of legal interpreting.

The leading contributors in both fields have been practitioners, such as lawyers and health care providers and, of course, interpreters, but a recent trend also sees specialists in linguistics and communication studies beginning to contribute, a development that will certainly lead to more comprehensive research, encompassing all the areas of CI.

It is beyond doubt that Japan has become a multi-cultural society. The CI studies of the past two decades have highlighted the importance of language mediation and communication, including interpreting, in this new 
and evolving society, and have contributed to providing a basis for creating an effective system to cope with this new and challenging social phenomenon.

\section{Bibliography}

Asada, Kazushige (1994). "Outline of Foreigners Case and Criminal Procedure". Journal of Criminal Law 33(4), 773-790.

Ebashi, Takashi (1990). "Saiban wo ukeru kenri to tsuyakunin wo tsukeru kenri (Right to trial and right to interpreter)". Review of Law and Political Science 87(4), 21-75.

Ishizaki, Masayuki, Kaoru Nishino \& Patricia Borgman (2004). "Medical Interpreting and LEP Patients in the USA". Interpretation Studies 4, 121-138.

KDDI Research Institute, Inc. (2005). Study on models of support for medical treatments of foreigners in Japan through information technology. KDDI Research Institute, Inc.

Kimura, Yuji (1998). "Dogo jiken wo kangaeru (An Idea on Dogo Case)". Journal of JJIA 11, 33 36.

Kondo, Masaomi (1988). "Japanese Interpreters in their Socio-cultural Context". META 33(1), Special Issue on the Japanese Translation Scene, 70-78.

Matsumoto, Masayuki, Sigeki Ishihara \& Osamu Watanabe (1992). Chokaku Shougaisha to Keiji Tetsuzuki (Hearing Impaired and Crinimal Procedures). Tokyo: Gyousei Press.

MIC Kanagawa (2006). Best Practice of Language and Health Care. MIC Kanagawa.

MITF (2006). Proceedings of Symposium: Challenge for Equal Access. MITF.

Mizuno, Makiko (1995). "Shiho-tsuyaku shikaku ninteiseido no kanousei ni tsuite (Possibility of Introducing Certification System for Legal Interpreters)". Jurist 1078, 100-105.

Mizuno, Makiko (2004). "Future Prospects of the European Legal Interpreting System". Interpretation Studies 4, 139-156. Japan Association for Interpretation Studies.

Mizuno, Makiko (2006). "Possibilities and Limitations for Legally Equivalent Interpreting of Written Judgments". Speech Communication Education 19, 113-131.

Nagao, Hiromi (2001). "Working Conditions of Court Interpreters in Japan”. Critical Link 3. Available on line at: http://www.criticallink.org/journals/6.pdf (consulted 23.09.2005).

Nishimatsu, Suzumi (2003). "Methodology in Judicial Interpreter and Translator Training: A Case of the Graduate School of Osaka University of Foreign Studies". Interpretation Studies 3, 103-120. Japan Association for Interpretation Studies.

Nishiyama, Sen (1988). "Simultaneous Interpreting in Japan and the Role of Television: A Personal Narration”. META 33(1), Special Issue on the Japanese Translation Scene, 64-69.

Okabe, Yasumasa (1991). "Amerika gasshukoku no houtei-tsuyakunin ni kansuru mondai (Issues of Court Interpreters in the United States)". Osaka University Law Review 40, 723-776.

Osaka Bar Association (1991). Symposium: Foreigners and Criminal Cases. Osaka Bar Association.

Pinkerton, Yoko (1996). “Are Interpreters Allowed to 'Edit'? A Comparison of Interpreting Principles between Japan and Australia”. Interpreting Research 11(6), Collected papers from "Interpreting Research", 137-148.

Shimane, Satoru (1992). "Gaikokujin higisha to sousa-tetsuzuki wo meguru shomondai (Issues Surrounding Foreign Suspects and Investigation Procedures)". The Journal of Police Science 45(10), 1-20. Tokyo: Tachibana-Shobo Press.

Tsuda, Mamoru (1997). "Human Rights Problems of Foreigners in Japan's Criminal Justice System”. Migration World Magazine 25, 1-2, 22-25.

Watanabe, Osamu \& Hiromi Nagao (eds) (1998). Foreigners and Criminal Proceedings. Tokyo: Seibundo Press.

Watanabe, Osamu, Hiromi Nagao \& Makiko Mizuno (2004). Legal Interpreting. Tokyo: Shohakusha Press.

Yamashita, Kiyoshi (ed.) (2001). Melbourne Case: The Individual Communications. The Defence Team for the Melbourne Case

1 The Multi-language Information Center Kanagawa, which is subsidized by the Kanagawa prefectural government.

2 The most well-known 40-hour-training course for health care interpreters by CCHCP. The CCHCP is based in Seattle, but it addresses broad cultural issues that impact the health of 
individuals and families in ethnic minority communities nation-wide.

3 Public Law 95-539 (28 October1978) Amended Public Law 100-702 (19 November 1988)

4 A Thai woman was accused of having murdered another Thai woman and was sentenced to eight years imprisonment with labour. This case was appealed in a higher court because the interpretation during the trial had been so poor that the defendant had not been able to communicate adequately. 